\title{
Abstracts of Regular Lectures
}

\author{
Sung Je Cho
}

\section{Understanding the Nature of the Geometric Work Through Its Development and Its Transformations*}

\begin{abstract}
Kuzniak Alain
Université Paris Diderot, France

alain.kuzniak@univ-paris-diderot.fr

The question of the teaching and learning of geometry has been profoundly renewed by the appearance of Dynamic Geometry Software (DGS). These new artefacts and tools have modified the nature of geometry by changing the methods of construction and validation. They also have profoundly altered the cognitive nature of student work, giving new meaning to visualisation and experimentation. In our presentation, we show how the study of some geneses (figural, instrumental and discursive) could clarify the transformation of geometric knowledge in school context. The argumentation is supported on the framework of Geometrical paradigms and Spaces for Geometric Work that articulates two basic views on a geometer's work: cognitive and epistemological.
\end{abstract}

Keywords: Geometric work, Visualization, Geometrical paradigm

\footnotetext{
S.J. Cho $(\square)$

Seoul National University, Seoul, Republic of Korea

e-mail: sungjcho@snu.ac.kr

(C) The Author(s) 2015 


\title{
Integration of Technology into Mathematics Teaching: Past, Present and Future*
}

\author{
Adnan Baki \\ Karadeniz Technical University, Turkey \\ abaki@ktu.edu.tr \\ This paper deals with my endeavor as a researcher and lecturer within the world \\ of educational computing to integrate technology into mathematics teaching. \\ I started with the book titled "New Horizons in Educational Computing". In this \\ book Saymor Papert enthusiastically says that computers as powerful learning tools \\ will change tomorrow's classrooms. It is difficult to use this potential of computers \\ for changing teacher's role and practice within an educational setting based on \\ telling and showing. It was not easy for me to shift from traditional notions of \\ teacher to constructivist teacher using Logo, Cabri and Geogebra as primary tools \\ for doing and exploring mathematics in classrooms.
}

\section{Investigating the Influence of Teachers' Pedagogical Beliefs and Reported Practices on Student Achievement in Basic Mathematics}

\begin{abstract}
Allan B.I. Bernardo
De La Salle University, Philippines

allan.bernardo@dlsu.edu.ph

Auxencia A. Limjap

De La Salle University, Philippines

auxencia.limjap@dlsu.edu.ph

This study investigated the pedagogical beliefs of the elementary and high school mathematics teachers. It sought to find out whether their pedagogical beliefs are consistent with the School Mathematics Tradition (SMT) and Inquiry Mathematics Tradition (IMT). It determined if there are differences in the pedagogical beliefs of math teachers in high, average and low performing schools (HPS, APS, LPS) at the elementary and secondary levels. It also determined how the pedagogical beliefs of teachers are related to their reported teaching practices. Results show that there is no difference in reported teaching practices in HPS, APS and LPS. Teachers' pedagogical beliefs but not practices might be related to the performance of their students. There was a clearer link between the performance level of the schools and the teachers' pedagogical beliefs. The qualitative data suggest that many teachers hold the native view that how students learn mathematics is determined by how they teach mathematics.
\end{abstract}

Keywords: Basic mathematics, Pedagogical beliefs, School mathematics tradition, Inquiry mathematics tradition. 


\title{
Developing Free Computer-Based Learning Objects \\ for High School Mathematics: Examples, Issues and Directions*
}

\author{
Humberto José Bortolossi \\ Fluminense Federal University, Brazil \\ hjbortol@vm.uff.br
}

In late 2007, the Brazilian government launched a grant program offering 42 million dollars to support the production of digital contents to high school level in the following areas: Portuguese, biology, chemistry, physics and mathematics. Of this amount, the CDME Project (http://www.cdme.im-uff.mat.br/) of the Fluminense Federal University won 124 thousand dollars to develop educational software, manipulative materials and audio clips to the area of mathematics. In this article, we report our experience (and what we learned from it) within this project, regarding the development of educational software as learning objects. We hope that the examples, issues and directions shown here are useful for other teams concerned about cost, time and didactic quality in the development of their applications and online teaching systems.

Keywords: Learning objects in mathematics, software development technologies, visualization in the teaching and learning of mathematics.

\section{Doing Research Within the Anthropological Theory of the Didactic: The Case of School Algebra*}

\author{
Marianna Bosch \\ Ramon Llull University, Spain \\ marianna.bosch@iqs.edu
}

Since its emergence in the early 80 s with the study of didactic transposition processes, the Anthropological Theory of the Didactic maintains a privileged relationship with school algebra and its diffusion, both in school and outside school. I have chosen this case study to introduce the main "gestures of research" promoted by this framework and the methodological tools used to help researchers detach from the dominant viewpoints of the institutions where teaching and learning processes take place or which affect these processes in the distance. The construction of alternative reference models concerning school algebra and teaching and learning processes leads to some recent teaching experiences that break down the established didactic contracts, raising new research questions that need more in-depth analysis in the way opened by the "procognitive paradigm".

Keywords: School algebra, Anthropologic theory of the didactic, Didactic transposition, Arithmetic calculation programme, Algebraization process 


\title{
Curriculum Reform and Mathematics Learning: Evidence from Two Longitudinal Studies*
}

\author{
Jinfa Cai \\ University of Delaware, USA \\ jcai@math.udel.edu
}

Drawing on longitudinal evidence from the LieCal project, issues related to mathematics curriculum reform and student learning are discussed. The LieCal Project was designed to longitudinally investigate the impact of a reform mathematics curriculum called the Connected Mathematics Program (CMP) in the United States on teachers' teaching and students' learning. Using a three-level conceptualization of curriculum (intended, implemented and attained), a variety of evidence from the LieCal Project is presented to show the impact of mathematics curriculum reform on teachers' teaching and students' learning. The findings from the two longitudinal studies in the LieCal project serve both to show the kind of impact curriculum has on teachers' teaching and students' learning and to suggest powerful ways researchers can investigate curriculum effect on both teaching and learning.

Keywords: Curriculum, Education reform, Mathematics learning, Longitudinal studies, LieCal Project, Problem solving, Algebra, Standards

\section{Mathematical Problem Solving Beyond School: Digital Tools and Students' Mathematical Representations*}

\author{
Susana Carreira \\ University of Algarve and University of Lisbon, Portugal \\ scarrei@ualg.pt \\ By looking at the global context of two inclusive mathematical problem solving \\ competitions, the Problem@Web Project intends to study young students' beyond- \\ school problem solving activity. The theoretical framework is aiming to integrate a \\ perspective on problem solving that emphasises understanding and expressing \\ thinking with a view on the representational practices connected to students' digital \\ mathematical performance. Two contextual problems involving motion are the \\ basis for the analysis of students' digital answers and an opportunity to look at the \\ ways in which their conceptualisations emerge from a blend of pictorial and \\ schematic digital representations.
}

Keywords: Problem solving, Expressing thinking, Digital mathematical performance, Competitions. 


\title{
Teaching Probability in Secondary School
}

\author{
Paulo Cezar Pinto Carvalho \\ IMPA and FGV, Brazil \\ pcezar@impa.br
}

Probability teaching in secondary school many times emphasizes computing probabilities as ratios of favourable to possible cases. Often, however, not enough attention is given to whether the possible cases are equally likely. We argue that being able to identify the adequateness of an equiprobable model for a given situation is a fundamental ability to be developed in secondary school. The role of simulation in understanding the meaning of computed probability values and realizing the power and limitations of probabilistic methods is also discussed.

Keywords: Probability, Modelling, Simulation, Secondary school.

\section{Mathematics is Alive!: Project Based Mathematics}

\author{
Kyung Yoon Chang \\ KonKuk University, Korea \\ kchang@konkuk.ac.kr
}

Mathematics is a structured body of knowledge invented to describe properties and solve problems around us but is considered merely as a collection of facts, concepts, and procedures. Mathematics is a hard and boring subject to many. Although Korean students showed top level performances in recent international studies, their affect toward mathematics and self-confidence level were at a surprisingly low level. Projects may give vitality to school mathematics and motivate students to pursue solutions to nontrivial real problems and create products.

In this lecture I will present arguments concerning project-based learning in mathematics. Working with projects making solid dissected models will be introduced and analysed with students' endeavours. Data was collected from pre-service secondary math teachers taking a geometry course at undergraduate or graduate level for 3 years.

In the process of engaging activities, making connections among concepts, integrating process and procedural knowledge, modifying their conjectures, and experiencing reflective thinking, pre-service secondary mathematics teachers illustrated their feelings of satisfaction and confidence. Technology took a crucial role in project-based learning, because students' endeavours could not be realized as the final products without the aid of it.

Mathematics is not mere artifacts but a reality. Mathematics is alive in project!

Keywords: Project based, Geometric model, Conic section, Affect, Technology. 


\title{
Weaving Exploration in the Process of Acquisition and Development of Mathematical Knowledge
}

\author{
Marcos Cherinda \\ Universidade Pedagógica Mozambique, Mozambique \\ mCherinda@up.ac.mz
}

This paper presents an experience of a process of gathering mathematical knowledge by exploration of artifacts of students' cultural environment - the mat twill weaving techniques and their resulting products as well. That process means starting from posing and reflecting on "why ...", "how ...", and "what if ..." questions related to the existence and gestalt of such artifacts, when one is manipulating them either physically or mentally. This highlights the Gerdes' research approach in the new research field called ethnomathematics. Furthermore, the paper brings the context of all that process, the classic theoretical framework on research methods in mathematics education, illustrating what does mean "doing mathematics", and how mathematics teachers can make their students feel themselves mathematics producers and owners, just by exploring those artifacts. The experience was gain both in and out of school settings but always leaded to know about the process of acquiring mathematical knowledge by the involved subjects.

\section{An Illustration of the Explanatory and Discovery Functions of Proof}

\author{
Michael de Villiers \\ University of KwaZulu-Natal, South Africa \\ profmd1@mweb.co.za
}

This paper provides an illustration of the explanatory and discovery function of proof with a geometric conjecture made by a Grade 11 learner. After logically explaining (proving) the result geometrically and algebraically, the result is generalized to other polygons by further reflection on the proof(s).

Keywords: Proof, Explanation, Discovery, Generalization, Viviani's theorem.

\section{Constructing Abstract Mathematical Knowledge in Context*}

Tommy Dreyfus

Tel Aviv University, Israel

tommyd@post.tau.ac.il

Understanding how students construct abstract mathematical knowledge is a central aim of research in mathematics education. Abstraction in Context (AiC) is a 
theoretical-methodological framework for studying students' processes of constructing abstract mathematical knowledge as they occur in a mathematical, social, curricular and learning-environmental context. AiC builds on ideas by Freudenthal, Davydov, and others. According to AiC, processes of abstraction have three stages: need, emergence and consolidation. The emergence of new (to the student) constructs is treated by means of a model of three observable epistemic actions: Recognizing, Building-with and Constructing-the RBC-model. This paper presents a theoretical and methodological introduction to $\mathrm{AiC}$ including to the RBC-model, and an overview of pertinent research studies.

Keywords: Abstraction, Knowledge construction, Context, RBC-model.

\title{
Digital Technology in Mathematics Education: Why It Works (Or Doesn't)*
}

\author{
Paul Drijvers
}

Freudenthal Institute

Utrecht University, the Netherlands

p.drijvers@uu.nl

The integration of digital technology confronts teachers, educators and researchers with many questions. What is the potential of ICT for learning and teaching, and which factors are decisive in making it work in the mathematics classroom? To investigate these questions, six cases from leading studies in the field are described, and decisive success factors are identified. This leads to the conclusion that crucial factors for the success of digital technology in mathematics education include the design of the digital tool and corresponding tasks exploiting the tool's pedagogical potential, the role of the teacher and the educational context.

Keywords: didactical function, digital technology, instrumentation.

\section{Mathematical Thinking Styles in School and Across Cultures*}

\author{
Rita Borromeo Ferri \\ Institute of Mathematics, University of Kassel, Germany \\ borromeo@mathematik.uni-kassel.de
}

A mathematical thinking style is the way in which an individual prefers to present, to understand and to think through, mathematical facts and connections by certain internal imaginations and/or externalized representations. In which way mathematical thinking styles (analytic, visual and integrated) are influence factors on the learning and teaching of mathematics is described on the basis of selected qualitative empirical studies from primary up to secondary school. Within the 
current MaTHSCu-project the styles are measured quantitatively by comparing mathematical thinking styles in eastern and western cultures. This study is introduced and first results are shown. Finally conclusions and implications for school are drawn.

\section{Learning to See: The Viewpoint of the Blind*}

\section{Lourdes Figueiras}

Universitat Autònoma de Barcelona, Spain

Lourdes.figueiras@uab.cat

Abraham Arcavi

Weizmann Institute of Science, Israel

abraham.arcavi@weizmann.ac.il

Visualization goes beyond "seeing". On the one hand, it includes other sensorial perceptions, relationships with previous experiences and knowledge, verbalization and more. On the other hand, visualization can develop also in the absence of vision. On the basis of these premises, we attempt to revise the processes of visualization in mathematics education by (a) analyzing learning and teaching of mathematics by blind students with an expert blind mathematics teacher, and (b) simulating blindness with mathematics teachers with normal vision.

Keywords: Visualization, Blind

\section{Issues and Concerns About Integration of ICT into the Teaching and Learning of Mathematics in Africa: Botswana Case*}

\section{Kgomotso Gertrude Garegae \\ University of Botswana, Botswana \\ garegaek@mopipi.ub.bw}

This paper discusses challenges that developing countries, especially African countries, face when trying to integrate ICT into the school curriculum particularly the mathematics curriculum. The general belief that the availability of ICT gadgets in schools guarantees the ICT integration in specific subjects, is challenged. Issues such as teachers' lack of relevant skills, shortage of teaching tools and unavailability of support staff act as an impediment to ICT accessibility in classrooms. The paper describes the development of infrastructure in Botswana and experiences pertaining to the school curriculum and argues that proper preparation for a smooth implementation of ICT infusion and integration is necessary.

Keywords: ICT integration in Africa, ICT availability and accessibility, ICT and the mathematics curriculum, ICT integration in Botswana schools 


\title{
Learning Mathematics in Secondary School: The Case of Mathematical Modelling Enabled by Technology*
}

\author{
Jonaki B Ghosh \\ University of Delhi, India \\ jonakibghosh@gmail.com
}

This article describes a study which was undertaken to investigate the impact of teaching mathematics using mathematical modelling and applications at senior secondary school level in India. While traditionally the emphasis in mathematics teaching in India is on the development of procedural skills, the study shows that the use of modelling and applications enabled by technology enhanced student's understanding of concepts and led them to explore mathematical ideas beyond their level. Using this approach, a balanced use of technology and paper pencil skills led to a deeper understanding of the subject.

Keywords: Mathematical modelling, Technology, Visualization, Exploration, Paper pencil skills

\section{Doing Mathematics in Teacher Preparation: Giving Space and Time to Think, Reflect, Share and Feel*}

\author{
Frédéric Gourdeau \\ Université Laval, Canada \\ Frederic.Gourdeau@mat.ulaval.ca
}

Describing the minimal mathematical content knowledge needed for secondary school teachers is not the most useful way to approach the mathematical preparation of teachers. Rather, focusing on the doing of mathematics, on the quality of their engagement with mathematics, is crucial. In doing so, I argue that the role of mathematicians in the mathematical preparation of teachers is not reduced but rather enhanced: it is work of a different nature than is often argued, leaning more on the expertise of the mathematician in the doing of mathematics than on his or her knowledge of the facts of mathematics.

This talk is based on work done at Université Laval (Québec, Canada) for the past 15 years, mostly with Bernard R. Hodgson. We have developed a series of courses for teachers (in pre-service training mostly) which aim to engage them fully in the doing of mathematics. What do we mean by engaging them fully in the doing of mathematics? How do we try to achieve this? We will describe our approach through some examples, outlining important aspects which need to be taken into account: for instance, allowing genuine exploration of mathematical problems, working on the communication of ones' understanding (paying attention to words, definitions and statements) and learning to identify mathematical processes. These aspects are generally largely independent of the actual mathematical topics at hand 
and, in that sense, the main objectives pursued in each of these courses have little to do with the precise mathematical content.

Even though our reflections are based on a specific curriculum in a specific setting, we believe that some of the reflections we wish to share will have resonance with many outside Canada.

Keywords: Teacher education, Doing of mathematics, Mathematics preparation, Mathematicians' role.

\title{
Resources, at the Core of Mathematics Teachers' Work*
}

\section{Ghislaine Gueudet}

GREAD, ESPE Bretagne UBO, France

Ghislaine.Gueudet@espe-bretagne.fr

Mathematics teachers work with resources in class and out of class. Textbooks, in particular, hold a central place in this material. Nevertheless, the available resources evolve, with an increasing amount of online resources: software, lesson plans, classroom videos etc.

This important change led us to propose a study of mathematics teachers documentation. Mathematics teachers select resources, combine them, use them, revise them, amongst others. Teachers' documentation is both this work and its outcome. Teachers' documentation work is central to their professional activity; it influences the professional activity, which evolves along what we call professional geneses.

In this conference, I introduce a specific perspective on teachers resources, which enlightens in particular the changes caused by the generalized use of Internet resources.

Keywords: Communities, Documentation, Internet, Professional development, Resources

\section{Mathematics Education Reform Movement in Indonesia*}

\author{
Sutarto Hadi \\ Lambung Mangkurat University, Indonesia \\ shadiunlam@gmail.com
}

The reform of mathematics education in Indonesia started in the mid-seventies. The reform movement reported in this lecture is the second attempt after the first movement to reform traditional mathematics to modern mathematics (1975-1990) was a complete failure. Several mathematicians have dedicated their expertise and experiences to rebuild mathematics education from the remnant of modern mathematics. Their concerns are focused particularly with the weakest group of students. After a long consideration they come to the decision to implement the theory of realistic mathematics education (RME) as a basic concept for developing the local 
theory of mathematics teaching and learning. They have the same view that RME could be a vehicle for improving mathematics teaching and learning and at the same time as a tool for social transformation. They began with four teacher education institutes and 12 pilot schools. RME has since expanded to 23 universities that supervise over 300 schools and has trained thousands of teachers. In this process of mathematics education reform the theory of RME has been transformed into PMRI, the Indonesian version of RME, and has been widely accepted as a movement to reform mathematics education.

Keywords: Mathematics learning, RME, Teacher education, PMRI

\title{
Emotions in Problem Solving*
}

\author{
Markku S. Hannula \\ University of Helsinki, Finland \\ markku.hannula@helsinki.fi
}

Emotions are important part of non-routine problem solving. A positive disposition to mathematics has a reciprocal relationship with achievement, both enhancing the other over time. In the process of solitary problem solving, emotions have a significant role in self-regulation, focusing attention and biasing cognitive processes. In social context, additional functions of emotions become apparent, such as interpersonal relations and social coordination of collaborative action. An illustrative case study presents the role of emotions in the problem solving process of one 10-year old Finnish student when he is solving an open problem of geometrical solids. The importance of emotions should be acknowledged also in teaching. Tasks should provide optimal challenge and feeling of control. The teacher can model the appropriate enthusiasm and emotion regulation. Joking and talking with a peer are important coping strategies for students.

Keywords: Emotion, Problem solving, Coping

\section{Freudenthal's Work Continues*}

\section{Marja van den Heuvel-Panhuizen}

Freudenthal Institute, Utrecht University, the Netherlands

m.vandenheuvel-panhuizen@uu.nl

In this paper I address a number of projects on elementary mathematics education carried out at the Utrecht University. The focus is on (1) using picture books to support kindergartners' development of mathematical understanding, (2) revealing mathematical potential of special needs students, and (3) conducting textbook analyses to disclose the learning opportunities that textbooks offer.

I discuss how these projects are grounded in the foundational work of Freudenthal and his collaborators in the past and how this will be continued. 
Keywords: Picture books, Special education, Subtraction, Textbook analysis, Didactics of mathematics

\title{
Hands That See, Hands That Speak: Investigating Relationships Between Sensory Activity, Forms of Communicating and Mathematical Cognition*
}

\author{
Lulu Healy \\ Universidade Bandeirante de São Paulo, Brazil \\ lulu@pq.cnpq.br
}

This contribution explores the role of the body's senses in the constitution of mathematical practices. It examines the mathematics activities of learners with disabilities, with the idea being that by identifying the differences and similarities in the practices of those whose knowledge of the world is mediated through different sensory channels, we might not only become better able to respond to their particular needs, but also to build more robust understandings of the relationships between experience and cognition more generally. To focus on connections between perceptual activities, material and semiotic resources and mathematical meanings, the discussion concentrates on the mathematical practices of learners who see with their hands or who speak with their hands. This discussion centres around two examples from our research with blind learners and deaf learners and, in particular, analyses the multiple roles played by their hands in mathematical activities.

Keywords: Blind mathematics learners, Deaf mathematics learners, Embodied cognition, Gestures.

\section{Teachers Learning Together: Pedagogical Reasoning in Mathematics Teachers' Collaborative Conversations*}

\author{
Ilana Seidel Horn \\ Vanderbilt University, USA \\ ilana.horn@vanderbilt.edu \\ In the United States, teaching is an isolated profession. At the same time, \\ ambitious forms of teaching have been shown to benefit from teacher collaboration. \\ What is it about collegial conversations that supports teachers' ongoing professional \\ learning? In this paper, I synthesize findings from prior studies on mathematics \\ teachers' collaborative conversations, focusing my analysis on collective peda- \\ gogical reasoning. I examine four facets of collegial conversations that support \\ refinements in this reasoning. These facets are: interactional organization, \\ engagement of individual teachers in a group, epistemic stance on mathematics
}


teaching, and locally negotiated standards of representational adequacy. Together, these aspects of teacher talk differently organize opportunities for professional learning.

Keywords: Professional learning, In-service teachers, Discourse analysis

\title{
Transforming Education Through Lesson Study: Thailand's Decade-Long Journey*
}

\author{
Maitree Inprasitha \\ Khon Kaen University, Thailand \\ inprasitha_crme@kku.ac.th
}

The development of teaching and the teaching profession are issues that countries around the world have been struggling to solve for many centuries. Lesson study, a Japanese way of professional development of teachers, dates back nearly 140 years, in 1872 the Meiji government invited foreign teachers to teach Japanese teachers about "whole class instruction" (Isoda 2007). Ironically, in 1999, Stigler and Hiebert brought back to the U.S. the same idea on how to present whole class instruction, "If you want to improve education, get teachers together to study the processes of teaching and learning in classrooms, and then devise ways to improve them" (Stigler 2004 cited in Fernandez and Yoshida 2004). Although the education reform movement around the world calls for effective reform tools or even ideas like Japanese lesson study, transferring those tools/ideas to other socio-cultural setting in other countries is not easy and always complicated. Thus, education reform movements sometimes support but sometimes hinder movement of society. Taking Japan as a case study, Japan has undergone the movement of society from agricultural to industrialized, to information, and now knowledge-based society during the two centuries since the late 18th century to the present. Not visible to outside people, an evolution in the approach to school has taken place in Japan, which supports the movement of society, which has not occurred in most developing countries, including Thailand. Thailand has looked to Japan for ideas and has been implementing Lesson Study since 2000 but with a unique approach to adapt. Thailand's experience with Lesson study has been shared with APEC member economies over the last six years and has been deemed "quite a success" in improvement of teaching and learning of mathematics. 


\title{
Dialectic on the Problem Solving Approach: Illustrating Hermeneutics as the Ground Theory for Lesson Study in Mathematics Education*
}

\author{
Masami Isoda \\ University of Tsukuba, Japan \\ isoda@criced.tsukuba.ac.jp \\ Lesson study is the major issue in mathematics education for developing and \\ sharing good practice and theorize a theory for teaching and curriculum develop- \\ ment. Hermeneutic efforts are the necessary activities for sharing objectives of the \\ lesson study and make them meaningful for further development. This paper \\ illustrate hermeneutic efforts with two examples for understanding the mind set for \\ lesson study. First example, the internet communication between classrooms in \\ Japan and Australia, demonstrates four types of interpretation activities for her- \\ meneutic effort: Understanding, Getting others' perspectives, Instruction from \\ experience (self-understanding), and the hermeneutic circle. Using these concepts, \\ we will illustrate the dialectic discussion amongst students in the problem solving \\ classroom engaged in a task involving fractions.
}

\section{History, Application, and Philosophy of Mathematics in Mathematics Education: Accessing and Assessing Students' Overview and Judgment*}

\section{Uffe Thomas Jankvist \\ Roskilde University, Denmark \\ utj@ruc.dk}

The Regular Lecture addresses the three dimensions of history, application, and philosophy of mathematics in the teaching and learning of mathematics. It is discussed how students' overview and judgment - interpreted as 'sets of views' and beliefs about mathematics as a discipline-may be developed and/or changed through teaching activities embracing all three dimensions of history, application, and philosophy. More precisely, an example of such a teaching activity for upper secondary school is described along with a method for both accessing and assessing students' overview and judgment. Examples of data analysis are given based on a concrete implementation of the teaching activity.

Keywords: History, applications, and philosophy of mathematics, Overview and judgment, Students' beliefs, views, and images of mathematics as a discipline. 


\title{
Teaching Mathematical Modeling in School Mathematics
}

\author{
Ok-Ki Kang \\ SungKyunKwan University, Korea \\ okkang@skku.edu \\ Jihwa Noh \\ University of Northern Iowa, USA \\ jihwa.noh@uni.edu \\ Modeling is a cyclical process of creating and modifying models of empirical \\ situations to understand them better and improve decisions. The role of modeling \\ and teaching mathematical modeling in school mathematics has received increasing \\ attention as generating authentic learning and revealing the ways of thinking that \\ produced it. In this paper and interactive lecture session, we will review a subset of \\ the related literature, discuss benefits and challenges in teaching and learning \\ mathematical modeling, and share our attempts to improve traditional textbook \\ problems so that they can become more authentic modeling activities and impli- \\ cations for instruction and assessment as well as for research.
}

Keywords: Models, Representations, Modeling activities, Teaching modeling.

\section{Implications from Polya and Krutetskii*}

\author{
Wan Kang \\ Seoul National University of Education, Korea \\ wkang@snue.ac.kr
}

Enhancing mathematical problem solving abilities, George Polya gave tremendous contribution to mathematics educators. He identified 4 steps in the problem solving process; (1) understand the problem, (2) devise a plan, (3) carry out the plan, and (4) look back and check. For each step, Polya revealed many useful habits of thinking in forms of questions and suggestions. V. A. Krutetskii analysed mathematical abilities of school children, which suggest valuable implementation to many trying to develop effective ways of expanding mathematical problem solving abilities. Krutetskii's research was inspecting mathematical behaviour in 3 stages of information gathering, processing, and retention. He concluded that mathematically able students show strong trends to gather information in more synthetic way, to process information in more effective, economic, and flexible way and to retain indispensable information more than inessential.

Keywords: Mathematical heuristics, Mathematical abilities, Elementary teacher education, G. Polya, V.A. Krutetskii 


\title{
Derivative or Derivation?
}

\author{
Matthias Kawski \\ Arizona State University, United States \\ kawski@asu.edu \\ In calculus, linear algebra, statistics, and many others, final exams commonly \\ consist largely of tasks that only demand applying algorithms that consist of only \\ algebraic manipulations. Rather than simply complaining about such training in \\ "mindless symbol manipulation" [MSM], we argue that it is critical to acknowledge \\ that it is precisely this characteristic of mathematics which is responsible in part for \\ its utility and success across so many aspects of modern societies. Modern math- \\ ematical notation and formalism allowed the figurative medieval trader to employ \\ assistants who could effectively do the bookkeeping, do the numbers, without \\ having to understand the meaning of the symbols and the origin of the rules. With \\ time, arithmetic was augmented by algebra, then by calculus. Today, every year \\ millions of students participate in this amazing endeavour of mastering the rules for \\ doing calculus, yet many of whom never understand what they do. From a popular \\ quote of V. I. Arnold: "Leibniz quite rapidly developed formal analysis [i.e. cal- \\ culus] ... in a form especially suitable to teach analysis by people who do not \\ understand it to people who will never understand it.
}

\section{The Social Dimension of Argumentation and Proof in Mathematics Classrooms}

\begin{abstract}
Christine Knipping
Universität Bremen, Germany

knipping@math.uni-bremen.de

Argumentation and proof have received increasing attention in mathematics education in recent years. However, social dimensions of proof and argumentation have not been emphasised. These included the social, argumentational dimension of proving in academic mathematical practice, the social process that transforms mathematical proving and argumentation in the context of school mathematics classrooms, and the interplay between the socio-cultural backgrounds of students and the social expectations around proving and argumentation in schools. Without adequate attention to these dimensions, there is a danger that classroom argumentation could become a social filter, emphasising students' pre-existing advantages and disadvantages. Attention to the structures of argumentations in mathematics classrooms combined with research on social dimensions can provide a better understanding of the filtering effect of argumentation in classrooms. This could provide a basis for minimising unexpected and undesirable consequences of a greater focus on argumentation and proof.
\end{abstract}

Keywords: Argumentation, proof, mathematics classrooms, equity, socio-cultural background. 


\title{
Constructionism: Theory of Learning or Theory of Design?*
}

\author{
Chronis Kynigos \\ University of Athens, Greece \\ kynigos@ppp.uoa.gr
}

Constructionism has established itself as an epistemological paradigm, a learning theory and a design framework, harnessing digital technologies as expressive media for students' generation of mathematical meanings individually and collaboratively. It was firstly elaborated in conjunction with the advent of digital media designed to be used for engagement with mathematics. Constructionist theory has since then been continually evolving dynamically and has extended its functionality from a structural set of lens to explanation and guidance for action. As a learning theory, the constructionist paradigm is unique in its attention to the ways in which meanings are generated during individual and collective bricolage with digital artefacts, influenced by negotiated changes students make to these artefacts and giving emphasis to ownership and production. The artefacts themselves constitute expressions of mathematical meanings and at the same time students continually express meanings by modulating them. As a design theory it has lent itself to a range of contexts such as the design of constructionist-minded interventions in schooling, the design of new constructionist media involving different kinds of expertise and the design of artifacts and activity plans by teachers as a means of professional development individually and in collective reflection contexts. It has also been used as a lens to study learning as a process of design. This paper will discuss some of the constructs which have or are emerging from the evolution of the theory and others which were seen as particularly useful in this process. Amongst them are the constructs of meaning generation through situated abstractions, re-structurations, half-baked microworlds, and the design and use of artifacts as boundary objects designed to facilitate crossings across community norms. It will provide examples from research in which I have been involved where the operationalization of these constructs enabled design and analysis of the data. It will further attempt to forge some connections with constructs which emerged from other theoretical frameworks in mathematics education and have not been used extensively in constructionist research, such as didactical design and guidance as seen through the lens of Anthropological Theory from the French school and the Theory of Instrumental Genesis.

Keywords: Constructionism, Design, Meaning generation, Theory networking, Digital media 


\title{
Adjacent Schools with Infinite Distance-Narratives from North Korean Mathematics Classrooms
}

\author{
Jung Hang Lee
}

Nyack College, USA

jhehlee@yahoo.com

This research addresses mathematics education in one of the most closed countries in the world, North Korea. North Korean secondary school mathematics education is examined through review of North Korea's social and educational structures as well as its political and ideological position. In-depth interviews were conducted with dislocated secondary school mathematics teachers and former students to understand their lived experiences in secondary school mathematics in North Korea. Participants responded to questions concerning typical ways teaching and learning were carried out in mathematics classes; the Workers' Party's influence in every aspect of education, from teacher education to curriculum and textbooks issued; and the impact the March of Suffering had on the teaching and learning of mathematics as well as its lingering effects in secondary mathematics education. One of the goals of this research was to provide a more realistic picture and background of secondary school mathematics education in North Korea. The participants came from different parts of North Korea and were interviewed based on their experiences in secondary school mathematics ranging anywhere between three to 25 years ago. Therefore, this collective interview analysis presents a solid viewpoint on secondary school mathematics in North Korea.

Keywords: North Korea, Secondary mathematics education, Interview.

\section{Mobile Linear Algebra with Sage*}

\author{
Sang-Gu Lee \\ Sungkyunkwan University, Korea \\ sglee@skku.edu
}

Over the last 20 years, our learning environment for linear algebra has changed dramatically mathematical tools take an important role in our classes.

Sage is popular mathematical software which was released in 2005. This software has efficient features to adapt the internet environment and it can cover most of mathematical problems, for example, algebra, combinatorics, numerical mathematics, calculus and linear algebra.

Nowadays there are more mobile/smartphones than the number of personal computers in the world. Furthermore, the most sophisticated smartphones have almost the same processing power as personal computer and it can be connected to the internet. For example, we can connect from mobile phone to any Sage server through the internet. We have developed over the years on Mobile mathematics with Smartphone for teaching linear algebra (Ko et al. 2009; Lee and Kim 2009; Lee et al. 2001). 
In this article, we introduce Sage and how we can use it in our linear algebra classes. We aim to show the mobile infrastructure of the Sage and the mobilelearning environment. We shall also introduce mobile contents for linear algebra using Sage. In fact, almost all the concepts of linear algebra can be easily covered.

Keywords: Mobile mathematics, Sage, Learning environment, Smartphone, Linear algebra

\title{
Discernment and Reasoning in Dynamic Geometry Environments*
}

\begin{abstract}
Allen Leung
Hong Kong Baptist University, Hong Kong

aylleung@hkbu.edu.hk

Dynamic Geometry Environments (DGE) give rise to a phenomenological domain where movement and variation together with visual and sensory-motor feedback can guide discernment of geometrical properties of figures. In particular, the drag-mode in DGE has been studied in pedagogical settings and gradually understood as a pedagogical tool that is conducive to mathematical reasoning, especially in the process of conjecture formation in geometry. The epistemic potential of the drag-mode in DGE lies in its relationship with the discernment of invariants. In this lecture, I will discuss means of discernment and reasoning for DGE based on a combined perspective that puts together elements from the Theory of Variation and the Maintaining Dragging Scheme. My focus is on an idea of invariant as the fundamental object of discernment. Furthermore, an idea of instrumented abduction is proposed to frame how such reasoning can be developed. Exploring by dragging is a powerful tool supporting geometrical reasoning. At the end, I will introduce a Dragging Exploration Principle that might help to cognitively connect the realm of DGE and the world of Euclidean Geometry.
\end{abstract}

Keywords: Dynamic geometry environments, Dragging, Variation, Abduction

\section{Riding the Third Wave: Negotiating Teacher and Students' Value Preferences Relating to Effective Mathematics Lesson*}

\author{
Chap Sam Lim \\ Universiti Sains Malaysia, Malaysia \\ cslim@usm.my \\ The "Third Wave" is an ongoing international collaborative mathematics edu- \\ cation research project, involving 10 countries conducted over the years 2009- \\ 2011. Adopting the theoretical framework of social cultural perspective, the project
}


aimed to explore the contextually-bound understanding and meaning of what counts as effective mathematics lesson from both the teachers and pupils' perspectives. This paper begins with a brief description of the Third Wave Study Project, the research framework and the general methodology used. Thereafter, it will concentrate on the main focus of the paper featuring a detailed discussion of the related findings from the Malaysian data. The data involved six mathematics teachers and 36 pupils from three types of primary schools. Multiple data sources were collected through classroom observations, photo-elicited focus group interviews with pupils and in-depth interviews with teachers. During each class lesson observation, the six selected pupils (as predetermined by their teacher) were given a digital camera to capture the moments or situations in the observed lesson that they perceived as effective. Pupils were then asked to elaborate what they meant by effective mathematics lesson based on the photographs that they have taken. Teachers were also interviewed individually immediately after each lesson observation and pupil's focus group interview. Findings of the study show that both teachers and pupils shared two co-values and two negotiated values in what they valued as an effective mathematics lesson. The two co-values are "board work" and "drill and practices" while the two negotiated values are "learning through mistakes" and "active student involvement". However, there are minor differences in teachers' and pupils' value preferences, for instance, pupils valued more of "clear explanation" from their teachers and active participation in classroom activities whereas teachers put emphasis on using different approaches to accommodate different types of pupils. More importantly, it was observed that an effective mathematics lesson is very much shaped by the continuous negotiation between teachers' and pupils' values and valuing. This paper ends with reflections on some possible implications and significant contributions of the study in mathematics education.

Keywords: Effective lesson, Expert/excellent teacher, Mathematics education, Primary School, Photo-elicited interview, Third wave, Values.

\title{
Learning Mathematics by Creative or Imitative Reasoning*
}

\author{
Johan Lithner \\ Umea University, Sweden \\ johan.lithner@umu.se
}

This paper presents (1a) a research framework for analysing learning difficulties related to rote learning and imitative reasoning, (1b) research insights based on that framework, (2a) a framework for research and design of more efficient learning opportunities through creative reasoning and (2b) some related ongoing research.

Keywords: Learning difficulties, Rote learning, Creative reasoning, Problem solving. 


\title{
Features of Exemplary Lessons Under the Curriculum Reform in China: A Case Study on Thirteen Elementary Mathematics Lessons*
}

\author{
Yunpeng Ma \\ Northeast Normal University, China \\ mayp@nenu.edu.cn \\ Dongchen Zhao \\ Northeast Normal University, China \\ dongchenzhao@hotmail.com
}

Dramatic changes in mathematics education in China have taken place since the new mathematics curriculum standard was implemented in 2001. What do new features of exemplary lessons appear under the context of the curriculum reform? This paper will answer this question by presenting a case study on 13 elementary mathematics lessons that were evaluated as excellent exemplary lessons by mathematics educators in China. This study found that, consistent with the ideas advocated by the new curriculum, the selected lessons demonstrated the features of emphasizing on student's overall development, connecting mathematics to real-life, providing students the opportunities for inquiring and collaborating, and teachers' exploiting various resources for teaching. Meanwhile, the selected lessons also shared other common features in the lesson structure, the interaction between teacher and students, and the classroom discourse. The results reveal that the exemplary lessons have practiced the advocated ideas of the current reform, while they also embodied some elements that might be the stable characteristics of Chinese mathematics education.

Keywords: Chinese mathematics classroom, Teaching practice reform, Exemplary lesson, Elementary mathematics

\section{Teachers, Students and Resources in Mathematics Laboratory*}

\author{
Michela Maschietto \\ University of Modena e Reggio Emilia, Italy \\ michela.maschietto@unimore.it \\ This paper deals with the methodology of mathematics laboratory from two \\ points of view: the first one concerns teacher education, the second one concerns \\ teaching experiments in classes. Mathematics laboratory (described in the Italian \\ national standards for mathematics for primary and secondary schools) can be \\ considered as a productive "place" where constructing mathematics meanings, \\ more a methodology than a physical place. It can be associated to inquiry based \\ learning for students. An example of mathematics laboratory with cultural artefacts \\ such as the mathematical machines (www.mmlab.unimore.it) is discussed.
}


Keywords: Mathematics laboratory, Instrumental genesis, Semiotic mediation, Mathematical machine, Teacher education.

\section{The Common Core State Standards in Mathematics*}

\section{William McCallum}

The University of Arizona, USA

wmc@math.arizona.edu

The US Common Core State Standards in Mathematics were released in 2009 and have been adopted by 45 states. We describe the background, process, and design principles of the standards.

Keywords: Standards, United States, Common Core.

\section{From Practical Geometry to the Laboratory Method: The Search for an Alternative to Euclid in the History of Teaching Geometry*}

\section{Marta Menghini \\ Sapienza Università di Roma, Italy \\ marta.menghini@uniroma1.it sentations of geometry. \\ Research on Mathematics Classroom Practice: An International Perspective*}

This paper wants to show how practical geometry, created to give a concrete help to people involved in trade, in land-surveying and even in astronomy, underwent a transformation that underlined its didactical value and turned it first into a way of teaching via problem solving and then into an experimental-intuitive teaching that could be an alternative to the deductive-rational teaching of geometry. This evolution will be highlighted using textbooks that proposed alternative pre-

Keywords: Practical geometry, History of mathematics education, Textbooks.

\section{Ida Ah Chee Mok}

The University of Hong Kong, Hong Kong iacmok@hku.hk

Research on Mathematics Classroom Practice encompasses very comprehensive themes and issues that may include any studies and scientific experiments happening inside the classroom, including consideration of the key agents in the 
classroom (the teachers and the students), undertaken with diversified research objectives and theoretical backgrounds. To a certain extent, seeking an international perspective provides some delineation of the topic. Studies will then focus on those issues already prioritised as of interest by existing international comparative studies and those issues seen as significant within an educational system. This lecture will draw upon the work of an international project, the Learner's Perspective Study (LPS), an international collaboration of 16 countries with the aim of examining in an integrated and comprehensive fashion the patterns of participation in competently taught eighth grade mathematics classrooms.

Keywords: Mathematics classroom practice, Cross-cultural practice, Teaching strategies, Learning tasks, Student perspective

\title{
Mathematical Literacy for Living in the Highly Information-and-Technology-Oriented in the 21st Century: Mathematics Education from the Perspective of Human Life in Society*
}

\author{
Eizo Nagasaki \\ Shizuoka University, Japan \\ eenagas@ipc.shizuoka.ac.jp \\ This paper discusses mathematical literacy for living in our highly information- \\ and- technology-oriented society in the 21 st century. First, it inquires into the \\ significance of thinking about mathematical literacy in terms of how it benefits \\ modern individuals, as well as modern society. A summary of the past trends of \\ mathematical literacy in Japan is given. This is followed by a consideration of a \\ framework for thinking about mathematical literacy in the future. Here, the focus is \\ on mathematical methods and the need to re-visit the meaning of studying math- \\ ematics. This is followed by a discussion of the design of school mathematics \\ curricula that aim to nurture mathematical literacy. The discussion includes an \\ examination of the general structure of school mathematics as it pertains to \\ mathematical literacy, and the framework of school mathematics that addresses \\ diversity. Concrete examples of the designs of school mathematics curricula based \\ on research on mathematics education in Japan to date are given. Lastly, the \\ maintenance and development of mathematical literacy outside school is touched \\ upon.
}




\title{
Exploring the Nature of the Transition to Geometric Proof Through Design Experiments from the Holistic Perspective*
}

\author{
Masakazu Okazaki \\ Okayama University, Japan \\ masakazu@okayama-u.ac.jp
}

The gap between empirical and deductive reasoning is a global problem that has produced many students who have difficulties learning proofs. In this paper, we explore the conditions that aid students in entering into proof learning and how they can increase their ability before learning proofs through design experiments. First we discuss the theoretical backgrounds of the holistic perspective and didactical situation theory, and set our research framework as the transition from empirical to theoretical recognition consisting of the three aspects of inference, figure, and social influence. Next, we report our design experiments in plane geometry redesigned for the seventh grade, and examine how students may enter the world of proof by learning geometric transformation and construction as summarized in the three aspects of the framework. Finally, we suggest key ideas for designing lessons that promote transition.

Keywords: Transition to geometric proof, Holistic perspective, Empirical and deductive reasoning

\section{Laying Foundations for Statistical Inference*}

\section{Maxine Pfannkuch}

The University of Auckland, New Zealand

m.pfannkuch@auckland.ac.nz

Chris J. Wild

The University of Auckland, New Zealand

c.wild@auckland.ac.nz

In this paper we give an overview of a five-year research project on the development of a conceptual pathway across the curriculum for learning inference. The rationale for why statistical inference should be part of students' learning experiences and some of our long deliberations on explicating the conceptual foundations necessary for a staged introduction to inference are described. Implementing such a pathway in classrooms required the development of new dynamic visualizations, verbalizations, ways of reasoning, learning trajectories and resource material, some of which will be elucidated. The trialing of the learning trajectories in many classrooms with students from age 13 to over 20, including some of the issues that arose, are briefly discussed. Questions arising from our approach to introducing students to inferential ideas are considered.

Keywords: Secondary-university students, Sampling variability, Visualizations, Verbalizations 


\title{
Mathematics Education in Cambodia from 1980 to 2012: Challenges and Perspectives 2025*
}

\author{
Chan Roath \\ Ministry of Education, Youth and Sport, Cambodia \\ chan.roath@moeys.gov.kh
}

The Kingdom of Cambodia was a world leader in technology and scientific understanding from the ninth to the fifteen century as the Khmer Empire. Unfortunately the Pol Pot regime destroyed the education system in Cambodia between 1975 and 1979. The process of rebuilding the educational system of Cambodia was started by collecting the surviving educated people and by adapting the slogan: "The one who knows more teaches the one who knows less and the latter transfer's knowledge to illiterates". Mathematics education in Cambodia currently faces many problems such as a lack of well qualified teachers, a lack of knowledge in curriculum development, text book writing, methodology of teaching and use of ICT. Currently no quality assurance mechanism is available to ensure Cambodia's mathematics curriculum is up to international standards. The relatively low salary of teachers in the Kingdom remains an impediment to our educations system as it provides little motivation for people to become teachers.

The Cambodian Mathematical Society (CMS) was established on the 4th of March 2005 and recognized by the Royal Government of Cambodia to play a part in addressing the problems and improving the capacity of mathematical education in Cambodia. CMS is committed to promoting mathematics as a key "enabling" discipline that underlies other key disciplines and is at the heart of economic, environmental and social development in Cambodia.

A successful outcome for mathematical education in Cambodia depends on the creation and implementation of developmental goals that are appropriate for Cambodia.

The CMS has identified goals that will be made priorities in addressing the needs of mathematical education in Cambodia. These goals include improving the level of qualification of Cambodian mathematical teachers, upgrading the mathematical curriculum to a modern and internationally competitive level, improving the quality of teaching materials and textbooks available in the Khmer language, improving the pedagogical methods of teaching mathematics, promoting and supporting the use of information communication and technology (ICT) in mathematical instruction and encouraging participation in international mathematical programs and competitions as well as developing such competitions further in Cambodia.

Keywords: Cambodia, Mathematics education, Teaching skill, Information technology, Human resource. 


\title{
The Challenges of Preparing a Mathematical Lecture for the Public*
}

\author{
Yvan Saint-Aubin \\ Université de Montréal, Canada \\ yvan.saint-aubin@umontreal.ca
}

As public curiosity and interest for science grow, mathematicians are invited more often to address a public that is not a classroom audience. Such a public talk should certainly convey "mathematical ideas", but it obviously differs from the classroom lesson. Preparing for such a talk offers therefore new challenges. I give examples from recent public lectures given by prominent mathematicians and by myself that try to tackle these challenges. I also reflect about how these efforts have changed my behavior in the classroom.

Keywords: Mathematical lecture, Public awareness, Public interest for mathematics, Science awareness, Mathematics communication.

\section{Computer Aided Assessment of Mathematics Using Stack*}

\section{Christopher Sangwin \\ University of Birmingham, United Kingdom \\ C.J.Sangwin@bham.ac.uk}

Assessment is a key component of all teaching and learning, and for many students is a key driver of their activity. This paper considers automatic computer aided assessment (CAA) of mathematics. With the rise of communications technology, this is a rapidly expanding field. Publishers are increasingly providing online support for textbooks with automated versions of exercises linked to the work in the book. There are an expanding range of purely online resources for students to use independently of formal instruction. There are a range of commercial and open source systems with varying levels of mathematical and pedagogic sophistication.

\section{Numerical Analysis as a Topic in School Mathematics*}

\author{
Shailesh A Shirali \\ Rishi Valley School, India \\ shailesh.shirali@gmail.com \\ Concerns about the divide between school mathematics and the discipline of \\ mathematics are known in math education circles. At the heart of the debate is the \\ sense that imperatives in school mathematics differ from those in the discipline of \\ mathematics. In the former case, the focus is on remembering mathematical facts, \\ mastering algorithms, and so on. In the latter case, the focus is on exploring,
}


conjecturing, proving or disproving conjectures, generalizing, and evolving concepts that unify. It is clearly of value to find ways to bridge the divide. Certain topics offer greater scope at the school level for doing significant mathematics; one such is the estimation of irrational quantities using rational operations. This problem is ideal for experimentation, forming conjectures, heuristic reasoning, and seeing the power of calculus. The underlying logic is easy to comprehend. It would therefore be very worthwhile if we could make such topics available to students in high school.

Keywords: Numerical analysis, School mathematics, Discipline of mathematics, estimation, Irrational quantity, Rational operation.

\title{
Visualizing Mathematics at University? Examples from Theory and Practice of a Linear Algebra Course*
}

\author{
Blanca Souto-Rubio \\ Universidad Complutense de Madrid, Spain \\ blancasr@mat.ucm.es
}

With this communication, I will try to promote a discussion on visualization adapted to university level: how I understand it, why may it be important to understand advanced mathematics and, mainly, how it is currently taught. With this aim, five examples - obtained by the observation and my reflective practice in a Linear Algebra course-will be presented. The analysis of these episodes will enable deeper understanding of some issues of visualization in this particular context: relevant characteristics of visualization in Linear Algebra, some obstacles and opportunities of teaching visualization and some actions needed to improve the teaching of visualization at university level.

Keywords: Visualization, Linear algebra, Teaching at university level, Participant Observation.

\section{On the Golden Ratio*}

\author{
Michel Spira \\ Universidade Federal de Minas Gerais, Brazil \\ michelspira@gmail.com \\ The alleged appearances of the Golden Ratio $\Phi$ in natural phenomena, art, \\ architecture and even literature have elevated it to a sort of mystical status inside \\ and outside of Mathematics. In this article we present a skeptical view on this. We \\ first discuss some of $\Phi$ 's properties and then show that these properties are just \\ particular cases of more general constructions. We then show how to find $\Phi$ when \\ one believes it is there to be found. At the end, we discuss briefly one of the \\ manifestations of the $\Phi$ cult.
}

Keywords: Golden ratio, Golden number, Geometry 


\title{
The International Assessment of Mathematical Literacy: Pisa 2012 Framework and Items*
}

\author{
Kaye Stacey \\ University of Melbourne, Australia \\ k.stacey@unimelb.edu.au
}

The OECD PISA international survey of mathematical literacy for 2012 is based on a new Framework and has several new constructs. New features include an improved definition of mathematical literacy; the separate reporting of mathematical processes involved in using mathematics to solve real world problems; a computer-based component to assess mathematical literacy as it is likely to be encountered in modern workplaces; and new questionnaire items targeting mathematics. Procedures for quality assurance that arise in the preparation of an assessment for use in many countries around the world are illustrated with some items and results from the 2011 international field trial. The paper will provide background for the interpretation of the results of the PISA 2012 survey, which were published in December 2013.

Keywords: Mathematical literacy, Assessment, Comparative studies, Computerbased assessment, Achievement, Mathematical competencies.

\section{Applications and Modelling Research in Secondary Classrooms: What Have We Learnt?*}

\begin{abstract}
Gloria Stillman
Australian Catholic University, Australia

gloria.stillman@acu.edu.au

This paper focuses on my 20 year program of research into the teaching and learning of applications and modelling in secondary classrooms. The focus areas include the impact of task context and prior knowledge of the task context during the solution of applications and modelling tasks, mathematical modelling in secondary school, and metacognition and modelling and applications. Some of the analysis tools used in this research are also presented.
\end{abstract}

Keywords: Modelling, Secondary school, Applications

\section{Conflicting Perspectives of Power, Identity, Access and Language Choice in Multilingual Teachers' Voices*}

\author{
Lyn Webb \\ Nelson Mandela Metropolitan University, South Africa \\ lyn.webb@nmmu.ac.za
}


Teachers in the Eastern Cape, South Africa teach mainly in English, which is not their home language. In order to elicit their inner voices about language conflicts and contradictions in their classrooms they were encouraged to write poetry about their perceptions of the impact of language in their lives. The most prevalent contradiction they expressed was the power and dominance of English juxtaposed against the subordination of their home languages. English gave them access to education and upward employment mobility, whereas they were excluded from various discourses when they used their home languages. Their home languages legitimised and defined their identities, but appeared to be negated in an educational and economic environment. Since the necessity for pupils to become fluent in English conflicted with the pupils' difficulties in understanding content knowledge expressed in English, the teachers faced a choice between teaching in English (for access to social goods) or their home language (for epistemological access), or both. The use of poetry evoked feelings and emotions that may not have been as obvious, or as evocative, if other data-gathering methods had been used. It appears that the self-reflection embodied in the poetry gave the teachers a sense of empowerment, self-realisation and solidarity.

Keywords: Multilingual teachers, Language, Power, Access, Identity, Language choice, Poetry

\section{What Does It Mean to Understand Some Mathematics?*}

\section{Zalman Usiskin \\ The University of Chicago, USA \\ z-usiskin@uchicago.edu}

Mathematical activity involves work with concepts and problems. Understanding mathematical activity in mathematics education is different for the policy maker, the mathematician, the teacher, and the student. This paper deals with the understanding of a concept in mathematics from the standpoint of the student learner. We make the case for the existence at least five dimensions to this understanding: the skill-algorithm dimension, the property-proof dimension, the use-application (modeling) dimension, the representation-metaphor dimension, and the history-culture dimension. We delineate these dimensions for two concepts: multiplication of fractions, and congruence in geometry.

Keywords: Curriculum, Mathematical understanding, Fractions, Congruence, Mathematical concepts 


\section{Mapping Mathematical Leaps of Insight*}

\section{Caroline Yoon}

The University of Auckland, New Zealand

c.yoon@auckland.ac.nz

Mathematical leaps of insight - those Aha! moments that seem so unpredictable, magical even - are often the result of a change in perception. A stubborn problem can yield a surprisingly simple solution when one changes the way one looks at it. In mathematics, these changes in perception are usually structural: new insights develop as one notices new mathematical objects, attributes, relationships and operations that are relevant to the problem at hand. This paper describes a novel analytical approach for studying these insights visually using "mathematical SPOT diagrams" (SPOT: Structures Perceived Over Time), which display evidence of the mathematical structures students perceive as they work on problems. SPOT diagrams are used to compare the conceptual development of two pairs of participants, who investigate whether a gradient (derivative) graph yields information about the relative heights of points on its antiderivative; one participant pair experiences a leap of insight, whereas the other does not. Each pair's SPOT diagrams reveal key differences in the structural features they attend to, which can account for the disparate outcomes in their conceptual development.

Keywords: Mathematical insight; Calculus; SPOT diagrams; Mathematical structure

\section{Mathematics Competition Questions: Their Pedagogical Values and an Alternative Approach of Classification*}

\section{Tin Lam Toh}

National Institute of Education, Nanyang Technological University, Singapore tinlam.toh@nie.edu.sg

In this paper, it is argued that the role of the various mathematics competitions could be expanded beyond helping the nation in identifying and developing the mathematically gifted students. Through an examination of some mathematics competition questions, it was identified that these competition questions could serve to help the general student population to (1) acquire mathematical problem solving processes through acquiring or developing a problem solving model; (2) learn mathematics beyond the constraint of the school mathematics curriculum; (3) deepen students' understanding of school mathematics; and (4) acquire mathematical techniques which are rendered obsolete by the evolving technology. With the availability of vast resource on competition questions, an alternative approach to classify the competition questions based on the function it could serve in the usual mathematics classroom is proposed.

Keywords: Mathematics competition, Problem solving, Classification 


\title{
The Examination System in China: The Case of Zhongkao Mathematics*
}

\author{
Yingkang $\mathrm{Wu}$ \\ East China Normal University, China \\ ykwu@math.ecnu.edu.cn
}

Examination is a critical issue in education system in China. Zhongkao is a kind of graduation examination of junior high school, and at the same time, the entrance examination to senior high school. This paper describes the structure, features and changes in zhongkao mathematics papers in China based on a detailed analysis of 48 selected zhongkao mathematics papers from eight regions in recent six years. It is observed that the zhongkao mathematics papers stress computation, reasoning, and relations among different mathematics topics, but are less emphasized on applications of mathematics in real context. There are obvious region differences in zhongkao mathematics papers, with regions from west economic zone relatively less demanding and regions from east and central economic zones more demanding. Changes like more process-oriented questions and more real context questions are found. Examples of examination items are given to illustrate the identified features and changes.

Keywords: Zhongkao mathematics, Examination, Features, Changes, Junior high school graduates

\section{Mathematics at University: The Anthropological Approach*}

\section{Carl Winsløw \\ University of Copenhagen, Denmark \\ winslow@ind.ku.dk}

Mathematics is studied in universities by a large number of students. At the same time it is a field of research for a (smaller) number of university teachers. What relations, if any, exist between university research and teaching of mathematics? Can research "support" teaching? What research and what teaching?

In this presentation we propose a theoretical framework to study these questions more precisely, based on the anthropological theory of didactics. As a main application, the links between the practices of mathematical research and university mathematics teaching are examined, in particular in the light of the dynamics between "exploring milieus" and "studying media".

Keywords: University mathematics, Tertiary, Anthropological theory of the didactical. 


\title{
Hidden Cultural Variables to Promote Mathematics and Mathematics Education-Are There Royal Roads?
}

\author{
Guenter Toerner \\ University of Duisburg-Essen, Germany \\ guenter.toerner@uni-due.de
}

Being a research mathematician as well as a researcher in mathematics education and teacher education the author is reflecting the history of mathematics and mathematics education in the last fifty years from the point of view as an executive committee member of a national mathematics society. Especially, he is interested in sociological aspects of mathematics learning and teaching.

It is self-evident for mathematics departments to recruit as many students as possible and to have as many as possible graduate successfully. However, the socalled success rate differs from country to country and is - in the country of the author-by no means pleasant. Are we as mathematicians aware of the various figures in our country, at our university?

The author also analysed the situation in his department as chair of the committee of education for which he is in charge for the European Mathematical Society. It is quite astonishing the cultural framework seems to influence the situation in the study of mathematics, e.g. the percentages of students studying mathematics in the group of all students differ enormously, they count $0.3 \%$ in the Netherlands and $2.8 \%$ in Germany. Of course, there are some obvious reasons and explanations and long-lasting strong traditions, but also there are some hidden variables. How do our learned societies reflect upon these parameters? Do they have master plans?

Mathematics at school needs friends, but who are the friends of mathematics? In some countries mathematicians and mathematics educators are fighting math wars, fortunately not in the author's country. There are very often quite rational explanations for the superfluous struggles, but how can these wars be ended and peace established. The author tries again to explain these issues from a European point of view and gives some recommendations. Shouldn't we internationalize these issues to develop joint initiatives?

Finally, we have to accept that teachers are the most influential people to promote mathematics. They are the stakeholders for mathematics education. Again, there are large differences between learned societies when it comes to caring for teachers and how to attract teachers. What is the percentage of teachers in our learned societies? How can we attract teachers to become members?

Since ICM Berlin in 1998, the German mathematical society has made large progress to acknowledge the work of teachers - at all grades - and to offer communication at eye level. Progress is small; however, we should be patient as we have to change attitudes on both sides. Recently we were successful to convince the Deutsche Telekom Stiftung for financing a national German institute of excellence for mathematics teacher education (DZLM) in which the author is involved. Again, 
some insights, ideas and recommendations are presented. What is the role mathematics at university might play to contribute to a continuous professional development of teachers for all grades?

\title{
Use of Student Mathematics Questioning to Promote Active Learning and Metacognition*
}

\author{
Khoon Yoong Wong \\ National Institute of Education, Nanyang Technological University, Singapore \\ khoonyoong.wong@nie.edu.sg
}

Asking questions is a critical step to advance one's learning. This lecture will cover two specific functions of training students to ask their own questions in order to promote active learning and metacognition. The first function is for students to ask themselves mathematical questions so that they learn to think like mathematicians who often advance knowledge by asking new questions and trying to solve them. This is also called problem posing, an important component of the "look back" step in the Polya's problem solving framework. The second function is for students to ask their teachers learning questions during lessons when they do not understand certain parts of the lessons. Students who are hesitant to ask learning questions need to be inducted into the habit of doing so, and a simple tool called Student Question Cards (SQC) can help to achieve this objective. These SQC cover four types of mathematics-related learning questions: meaning, method, reasoning, and applications. In a pilot study involving Grades 4 and 7 Singapore students, every student was given a set of these laminated cards. During lessons, the teacher paused two or three times and required the students to select questions from SQC to ask to clarify their doubts. This reverses the normal roles of teacher and students during classroom interactions. Teachers and students in this pilot study expressed mixed responses to the use of SQC. These two functions of student mathematics questioning have the potential to promote active learning of mathematics among school students through strengthening their metacognitive awareness and control. To realize this potential, teachers need to pay due attention to the science, technology, and art of student questioning.

Keywords: Student questions, Problem posing, Metacognition, Buddha, Confucius, Socratic dialogue

Open Access This chapter is distributed under the terms of the Creative Commons Attribution Noncommercial License, which permits any noncommercial use, distribution, and reproduction in any medium, provided the original author(s) and source are credited. 